\title{
Violência obstétrica e reflexos na vida da mulher: Uma revisão integrativa
}

\author{
Obstetric violence and its impact on women's lives: An integrative review \\ Violencia obstétrica y reflexiones sobre la vida de las mujeres: Una revisión integradora
}

\begin{abstract}
Resumo
Objetivou-se analisar nas evidências científicas os reflexos da violência obstétrica na vida da mulher no período gestacional. Foi realizado um estudo de revisão integrativa da literatura com busca nas bases de dados da Biblioteca Virtual em Saúde (BVS), SCIELO, LILACS, BDENF, com os seguintes descritores presentes no DECS: "Violência"; "Obstetrícia"; "Saúde da mulher". Foram selecionados 1371 artigos ao todo, logo após foram aplicados os critérios de inclusão e foram selecionados 218 para leitura de títulos e resumos. Após essa leitura foram selecionados 13 artigos que atendiam ao objetivo da pesquisa para compor o trabalho. Os resultados do estudo evidenciaram que fatores socioeconômicos, medo, insegurança, carência da informação sobre seus direitos durante o período gravídico puerperal. Conclui-se que as gestantes precisam conhecer e exigir que seus direitos e decisões sejam respeitadas durante a gestação. Dessa forma, é necessário à capacitação e empatia do profissional de saúde além da implementação de estratégias para mudar positivamente esse cenário.
\end{abstract}

Palavras-chave: Violência; Obstetrícia; Saúde da mulher.

\begin{abstract}
The objective was to analyze the scientific evidence on the consequences of obstetric violence in women's lives during pregnancy. An integrative literature review study was conducted by searching the databases of the Virtual Health Library (VHL), SCIELO, LILACS, BDENF, with the following descriptors present in DECS: "Violence"; "Obstetrics"; "Women's health". 1371 articles were selected in total, then the inclusion criteria were applied and 218 were selected for reading the titles and abstracts. After this reading were selected 13 articles that met the research objective to compose the work. The results of the study showed that socioeconomic factors, fear, insecurity, lack of information about their rights during pregnancy and puerperium. We conclude that pregnant women need to know and demand that their rights and decisions be respected during pregnancy. Thus, it is necessary the training and empathy of health professionals in addition to the implementation of strategies to positively change this scenario.
\end{abstract}

Keywords: Violence; Obstetrics; Women's Health.

\section{Resumen}

El objetivo es analizaren las evidencias científicas los reflejos de la violencia obstétrica en la vida de la mujer en el período de gestación. Se realizó un estudio de revisión bibliográfica integradora con búsqueda en las bases de datos de la Biblioteca Virtual de Salud (BVS), SCIELO, LILACS, BDENF, con los siguientes descriptores presentes en DECS: "Violencia"; "Obstetricia"; "Salud de la mujer". Se seleccionaron 1371 artículos en total, luego se aplicaron los criterios de inclusión y se seleccionaron 218 para la lectura de los títulos y resúmenes. Tras la lectura se seleccionaron 13 artículos que cumplían el objetivo de la investigación para componer el trabajo. Los resultados del estudio mostraron que los factores socioeconómicos, el miedo, la inseguridad, la falta de información sobre sus derechos durante el embarazo y el parto. Se concluye que las mujeres embarazadas deben conocer y exigir que se respeten sus derechos y decisiones durante el embarazo. Por ello, es necesaria la formación y la empatía de los profesionales de la salud además de la implementación de estrategias para cambiar positivamente este escenario.

Palabras clave: Violencia; Obstetricia; Salud de la mujer. 


\section{Introdução}

A violência obstétrica (VO) se caracteriza de diversas formas, sendo um termo usado no Brasil para referir-se as práticas agressivas ou invasivas contra gestantes e puérperas, em que essas ações podem ser cometida por qualquer profissional da saúde que negligencie assistência a parturiente, além de violências verbais, físicas e psicológicas, assim como o uso de tecnologias e procedimentos desnecessários durante o ciclo gravídico-puerperal sem o consentimento da parturiente, impedindo a autonomia da gestante sobre seu próprio corpo (Oliveira et al.,2019).

Desse modo, a violência obstétrica é definida como qualquer conduta realizada por profissionais da saúde, caracterizando como crime comissivo ou crime omissivo, levando à apropriação indevida por imposição de mãos sobre diferentes partes do corpo sem o consentimento da parturiente. Exteriorizando em tratamento desumano, ferindo os princípios dos direitos individuais da gestante, tendo impacto negativo na qualidade de vida e contribuindo com efeitos indesejáveis tanto para a mãe quanto para o bebê (Brito; Oliveira \& Costa, 2020).

Segundo os autores Nascimento et al., (2019) 46\% dos partos realizados na rede pública e $88 \%$ na rede privada foram cesarianas. É indubitável que essa prática possa salvar vidas quando for necessário, em contrapartida existem fatores que corroboram para a realização da tal prática sem necessidade, ou seja, a conveniência e comodidade dos profissionais, submetendo a mãe e o bebê a riscos inerentes. Em consonância com outros estudos segundo os autores Lanky et al., (2019) 12,6\% das mulheres que sofreram algum tipo de violência obstétrica são solteiras ou desconhecem o pai da criança e possuem baixa renda, o que sugere uma vulnerabilidade com relação a situação vivenciada e as condições na qual está inserida.

Além disso, as gestantes têm o direito de receber os cuidados obstétricos durante toda a gestação e após o parto, bem como receber tratamento sem danos e maus-tratos, além de obter informações e/ou consentimento sobre qualquer procedimento realizado em seu corpo, esclarecido com possibilidade de recusas e respeito às suas escolhas, sendo inviável proibir um acompanhante durante a internação na unidade obstétrica e recebendo os cuidados dos profissionais de saúde com liberdade e autonomia (Brito; Oliveira \& Costa, 2020).

Por outro lado, de acordo com pesquisas realizadas pela Fundação Perseu Abramo em parceria com o SESC, comprova que no Brasil, uma a cada quatro mulheres sofrem algum tipo de violência durante o trabalho de parto. Essas agressões nem sempre são percebidas pelas parturientes, por mais que se sintam violadas acreditam que se trata de procedimentos rotineiros do trabalho de parto, porém, a experiência traumática acarreta sequelas que a mulher leva ao longo da vida. Dados que perduram até a data atual e não foram refutados por nenhum órgão ou estudo com amostragem (Aguiar; D’Oliveira \& Schraiber, 2013).

Considerando a importância de debater e combater essa realidade, que pode ser modificada com a humanização da assistência a gestante, bem como a empatia por parte dos profissionais. Deve se visar estratégias bem vistas para diminuir essa prática como a implantação da Rede Cegonha, pois prioriza o atendimento humanizado as mulheres grávidas, minimizando a mortalidade materna e neonatal, oferecendo assistência humanizada ao parto, aborto e puerpério (Moura et al., 2018).

Nessa perspectiva, o estudo se justifica pela importância de estudar a Violência obstétrica e reflexos na vida da mulher, além de conhecer mais sobre a vivência das gestantes que sofrem ou que já sofreram violência obstétrica, dentre seus malefícios, dificuldades e negligência na assistência por parte dos familiares e profissionais da saúde, tirando o direito de autonomia nas tomadas de decisões da mulher. Identificando e contribuindo para a melhoria da assistência dos profissionais que queiram mudar essa realidade das redes públicas e privadas de saúde.

Assim o estudo é de grande relevância uma vez que proporcionará informações atualizadas sobre a temática, que poderão ser utilizados por estudantes e profissionais da saúde, fornecendo dados que servirá como subsídio para outras pesquisas e contribuirá para a melhoria da assistência dos profissionais de saúde. 
Espera-se que possa contribuir com informações relevantes para que as gestantes tenham o conhecimento dos principais direitos que lhe é assegurado, bem como os profissionais possam atuar na assistência a gestante com empatia e um olhar mais holístico, prestando um cuidado digno e exaltando a autonomia da gestante no trabalho de parto.

Nesse contexto, a pesquisa tem como questão norteadora a seguinte pergunta: Quais evidências científicas de como a violência obstétrica interfere na vida da mulher? Apresentando como objetivo geral descrever baseado nas evidências científicas como a violência a obstétrica interfere na vida da mulher.

\section{Metodologia}

Realizou-se um estudo de revisão integrativa da literatura, sobre as principais evidências científicas publicadas acerca dos reflexos na vida da mulher que podem ser ocasionados pela violência vivenciada pelas gestantes com enfoque nos fatores que contribuem para desencadeamento do trauma e medo no momento do parto.

A revisão integrativa ocorre em etapas sendo a primeira etapa a definição da questão norteadora ou pergunta da pesquisa; na segunda etapa são estabelecidos os parâmetros de inclusão e exclusão; na terceira etapa ocorre a análise dos estudos préselecionados e selecionados; quarta etapa categoriza-se os artigos designados; quinta etapa interpretam-se os resultados e por fim, na sexta etapa os resultados da revisão são evidenciados (Galvão \& Pereira, 2014).

Para a busca de dados foram usadas como fontes de coleta as plataformas online de pesquisa da Scientific Eletronic Library Online (SCIELO), Biblioteca Virtual em Saúde (BVS), Literatura Latino-americana e do Caribe em Ciências da Saúde (LILACS), Base de dados bibliográficas especializada na área de Enfermagem (BDENF), Sistema Online de Busca e Análise de Literatura Médica (MEDLINE) e Google Acadêmico. Para escolhas dos artigos, os descritores utilizados foram: "Violência", "Obstetrícia", "Saúde da Mulher". A busca dos artigos foi realizada com o operador booleano "AND”.

Como critérios de inclusão foram selecionados artigos indexados em periódicos nacionais e internacionais, disponibilizados na íntegra (texto completo), em língua portuguesa, inglesa e espanhol, que apresentaram como assunto principal violência obstétrica e compreendido no período de 2016 a 2021. Foram excluídos os artigos que não pertenciam ao período compreendido no estudo, além de artigos duplicados e publicações que não se adequaram aos critérios propostos.

Somando-se todas as bases de dados, foram 1371 artigos. Após a leitura dos títulos dos artigos, notou-se que alguns deles se repetiram nas diferentes bases e outros não preenchiam os critérios deste estudo. Foram selecionados 218 artigos para leitura do resumo e excluídos os que não correspondiam ao propósito deste estudo. Após a leitura dos resumos, foram selecionados 13 artigos para análise e categorização, conforme a Figura 1 apresenta. 
Figura 1: Mecanismo de busca para a seleção dos estudos. Teresina, 2021.

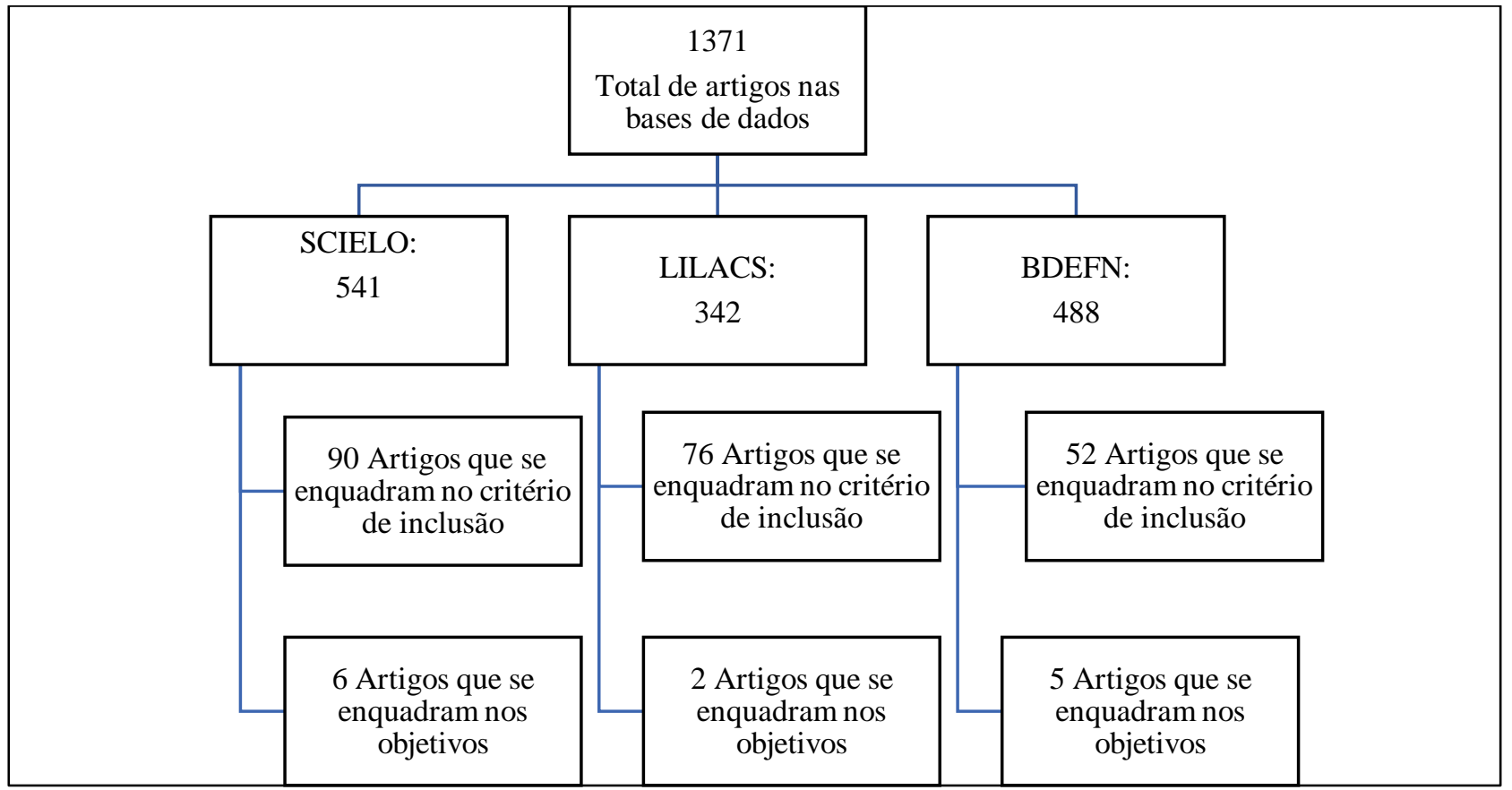

Fonte: Pesquisa direta em base de dados. Teresina-PI, 2021.

A análise do conteúdo dos artigos foi realizada por meio de leitura criteriosa na íntegra, que favoreceu a organização das informações e extração das evidências relacionadas aos objetivos propostos.

\section{Resultados}

A partir da leitura e análise do material encontrado, foram agrupadas informações relevantes dos artigos e foram organizados inicialmente em tabelas e quadros para um melhor entendimento e compreensão. A Tabela 1 apresenta a distribuição das produções científicas, segundo período de publicação, abordagem metodológica e pelo periódico de publicação. 
Tabela 1: Distribuição dos artigos de acordo com o ano, abordagem metodológica e pelo periódico de publicação. Teresina, 2021.

\begin{tabular}{lll}
\hline & Variáveis & \\
\hline ANO DE PUBLICAÇÃO & $\mathbf{N}^{\mathbf{o}}$ & $\%$ \\
2020 & 04 & 30,7 \\
\hline 2019 & 07 & 53,8 \\
\hline 2018 & 01 & 7,9 \\
\hline 2016 & 01 & 7,9 \\
\hline ABORDAGEM METODOLOGICA & $\mathbf{N}^{\mathbf{0}}$ & $\mathbf{\%}$ \\
\hline Qualitativa & 10 & 76,9 \\
\hline Quantitativa & 2 & 7,9 \\
\hline Quanti/qualitativa & 1 & $\mathbf{\%}$ \\
\hline PERIÓDICOS DE PUBLICAÇÃO & $\mathbf{N}^{\mathbf{0}}$ & 7,9 \\
\hline Revista de Enfermagem UFPE online & 1 & 7,9 \\
\hline Revista enfermagem UERJ & 1 & $\%$ \\
\hline
\end{tabular}

Fonte: Autores.

Em relação à abordagem metodológica, a que predominou foi a quantitativa, sendo esta de bastante relevância uma vez que permite reunir dados de forma objetiva por estatísticas que conferem maior precisão às informações. A abordagem qualitativa é relevante por enfatizar no caráter subjetivo do objeto examinado, estudando as suas particularidades e experiências individuais.

Em relação aos periódicos de publicação, verificou-se uma diversificação, onde quase todos os trabalhos foram publicados em um periódico diferente, repetindo-se apenas a Revista Min. Enferm. e Revista Nursing. Foram obtidos 13 trabalhos científicos que foram lidos na íntegra e em seguida, distribuídos em um quadro de forma resumida nas seguintes variáveis: título, ano e principais resultados (Quadro 1). Os artigos foram enumerados do 1 ao 13 para facilitar a análise de identificação das etapas.

Quadro 1: Distribuição dos estudos de acordo com Título, ano, autores, principais resultados. Teresina, 2021.

\begin{tabular}{|c|c|c|c|c|}
\hline $\mathbf{N}^{\mathbf{o}}$ & TÍTULO & ANO & AUTORES & PRINCIPAIS RESULTADOS \\
\hline 1 & $\begin{array}{l}\text { Vivências de puérperas frente à } \\
\text { atuação da equipe de } \\
\text { enfermagem durante o trabalho } \\
\text { de parto }\end{array}$ & 2020 & $\begin{array}{l}\text { ALMEIDA S. S. } \\
\text { R; et al. }\end{array}$ & $\begin{array}{l}\text { Evidenciou-se que a atuação da equipe de enfermagem foi } \\
\text { satisfatória durante o processo de trabalho de parto, sob o ponto de } \\
\text { vista das mulheres, demonstrando preparo para atender esse perfil } \\
\text { de clientela. }\end{array}$ \\
\hline 2 & $\begin{array}{l}\text { Fatores associados à violência } \\
\text { obstétrica na assistência ao } \\
\text { parto vaginal em uma } \\
\text { maternidade de alta } \\
\text { complexidade em Recife, } \\
\text { Pernambuco. }\end{array}$ & 2016 & $\begin{array}{l}\text { ANDRADE, P. } \\
\text { O. N, et al. }\end{array}$ & $\begin{array}{l}\text { Dentre as variáveis estudas, observou-se associação significante } \\
\text { com a violência obstétrica mulheres que não possuíam ensino médio } \\
\text { completo e aquelas assistidas por profissional médico. }\end{array}$ \\
\hline
\end{tabular}




\begin{tabular}{|c|c|c|c|c|}
\hline 3 & $\begin{array}{l}\text { Experiência das mulheres no } \\
\text { gestar e parir fetos anencéfalos: } \\
\text { as múltiplas faces da violência } \\
\text { obstétrica. }\end{array}$ & 2019 & $\begin{array}{l}\text { FERNANDES, } \\
\text { I. B, et al. }\end{array}$ & $\begin{array}{l}\text { A negação dos direitos das mulheres em vários aspectos, } \\
\text { especialmente a negação e julgamento moral das escolhas de } \\
\text { interromper ou não a gestação; a negação da assistência e tratamento } \\
\text { adequados; e negligência e abusos verbal e físico praticados contra } \\
\text { as entrevistadas, demonstrando que a violência obstétrica está } \\
\text { presente nas práticas cotidianas dos profissionais de saúde e, mais } \\
\text { do que isso, é banalizada e consentida. Apesar de terem sido } \\
\text { assistidas em uma maternidade de referência para o atendimento de } \\
\text { gestantes apresentando risco fetal e vivenciarem uma condição já } \\
\text { por si frágil, essas mulheres foram alvo de violência obstétrica em } \\
\text { várias dimensões. }\end{array}$ \\
\hline 4 & $\begin{array}{l}\text { Percepção e ações de doulas no } \\
\text { processo de humanização do } \\
\text { parto. }\end{array}$ & 2019 & $\begin{array}{l}\text { GRECIA R. M. } \\
\text { L; et al. }\end{array}$ & $\begin{array}{l}\text { O trabalho de doulas no acompanhamento de parturientes mostrou } \\
\text { que elas desenvolvem significativa relação dialógica com mulheres } \\
\text { durante o parto, contribuindo para a redução, especialmente, da } \\
\text { ansiedade, providenciando apoio emocional para o estabelecimento } \\
\text { do conforto maternal e da conexão da gestante com seus familiares } \\
\text { e com os profissionais de saúde. }\end{array}$ \\
\hline 5 & $\begin{array}{l}\text { Violência obstétrica: influência } \\
\text { da Exposição Sentidos do } \\
\text { Nascer na vivência das } \\
\text { gestantes. }\end{array}$ & 2018 & $\begin{array}{l}\text { LANKY, Sônia; } \\
\text { et al. }\end{array}$ & $\begin{array}{l}\text { A violência obstétrica é uma situação de importância em saúde da } \\
\text { mulher e da criança e influencia a cultura e a percepção sobre o parto } \\
\text { pela sociedade. Entretanto, o relato espontâneo de VO por apenas } \\
12,6 \% \text { das mulheres reflete o desconhecimento e subestimação do } \\
\text { problema. }\end{array}$ \\
\hline 6 & $\begin{array}{l}\text { O plano individual de parto } \\
\text { como estratégia de ensino- } \\
\text { aprendizagem das boas práticas } \\
\text { de atenção obstétrica }\end{array}$ & 2019 & $\begin{array}{l}\text { NARCHI Z. N; } \\
\text { et al. }\end{array}$ & $\begin{array}{l}\text { Indicam a necessidade da abordagem teórica e prática do plano de } \\
\text { parto também na formação dos enfermeiros, pois eles são os } \\
\text { principais atores da atenção às mulheres nas unidades básicas de } \\
\text { saúde. }\end{array}$ \\
\hline 7 & $\begin{array}{l}\text { Conhecimentos e experiências } \\
\text { de violência obstétrica em } \\
\text { mulheres que vivenciaram a } \\
\text { experiência do parto }\end{array}$ & 2019 & $\begin{array}{l}\text { NASCIMENTO, } \\
\text { S. L. et al. }\end{array}$ & $\begin{array}{l}\text { Urge a necessidade de implementação de medidas que assegurem } \\
\text { assistência humanizada e estratégias de empoderamento das } \\
\text { mulheres de modo que passem a ser protagonistas no ato de } \\
\text { parturição. }\end{array}$ \\
\hline 8 & $\begin{array}{l}\text { Vivências de violência } \\
\text { obstétrica experimentadas por } \\
\text { parturientes. }\end{array}$ & 2019 & $\begin{array}{l}\text { OLIVEIRA, M. } \\
\text { S. S. et al. }\end{array}$ & $\begin{array}{l}\text { É preciso uma assistência humanizada e qualificada a estas mulheres } \\
\text { neste momento tão delicado e importante de suas vidas. }\end{array}$ \\
\hline 9 & $\begin{array}{l}\text { Atuação da enfermeira } \\
\text { obstétrica na assistência ao } \\
\text { trabalho de parto e parto }\end{array}$ & 2019 & $\begin{array}{l}\text { SANCHES L. T. } \\
\text { E. M; et al. }\end{array}$ & $\begin{array}{l}\text { Foram revelados desafios a serem enfrentados pelas profissionais, } \\
\text { que justificam o fato de que mesmo a enfermeira estando presente } \\
\text { nesses momentos, nem sempre é possível garantir um cuidado ideal, } \\
\text { nem um acolhimento fidedigno, e que uma família que não entende } \\
\text { e nem respeita o tempo que a mãe e o bebê precisam, são problemas } \\
\text { comuns e que prejudicam o bom andamento desse momento. }\end{array}$ \\
\hline 10 & $\begin{array}{l}\text { O saber das puérperas sobre } \\
\text { violência obstétrica }\end{array}$ & 2019 & $\begin{array}{l}\text { SILVA, F. C, et } \\
\text { al. }\end{array}$ & $\begin{array}{l}\text { Embora a ocorrência de violência obstétrica não aconteça somente } \\
\text { no âmbito da saúde pública, mas também no setor privado, que há } \\
\text { referências de que a maior incidência de práticas violentas ocorra } \\
\text { mais nos hospitais públicos nos quais os clientes possuem maior }\end{array}$ \\
\hline
\end{tabular}




\begin{tabular}{|c|c|c|c|c|}
\hline & & & & $\begin{array}{l}\text { diversidade étnica e menor nível de escolaridade, influenciando a } \\
\text { própria percepção do parto. }\end{array}$ \\
\hline 11 & $\begin{array}{l}\text { Percepção das parturientes } \\
\text { sobre violência obstétrica: a dor } \\
\text { que querem calar }\end{array}$ & 2020 & $\begin{array}{l}\text { TEXEIRA, P.C, } \\
\text { et al. }\end{array}$ & $\begin{array}{l}\text { Como estratégia para evitar que as mulheres sofram esses impactos, } \\
\text { deve-se garantir um atendimento livre de qualquer preconceito e } \\
\text { discriminação, assim como fornecer a essas mulheres uma } \\
\text { orientação satisfatória durante o pré-natal a respeito das fases do } \\
\text { trabalho de parto, vias de parto, e direitos das mesmas, e a } \\
\text { importância do plano de parto como uma forma documental de } \\
\text { resguardo das suas escolhas. }\end{array}$ \\
\hline 12 & $\begin{array}{lcc}\text { Mulheres em privação de } & \text { de } \\
\text { liberdade: } \quad \text { narrativas } & \text { de } \\
\text { des(assistência) obstétrica } & \end{array}$ & 2020 & $\begin{array}{l}\text { SILVA, J. B, et } \\
\text { al. }\end{array}$ & $\begin{array}{l}\text { Foi possível identificar, nas oralidades dos discursos, fragilidades na } \\
\text { atenção à saúde das mulheres no ciclo gravídico-puerperal. Tais } \\
\text { dificuldades concernem à des(assistência) no pré-natal, vivência não } \\
\text { percebida de violência obstétrica, sentimentos de abandono no parto } \\
\text { e falta de ambiente adequado para os recém-nascidos. }\end{array}$ \\
\hline 13 & $\begin{array}{l}\text { Violência obstétrica na } \\
\text { percepção de puérperas }\end{array}$ & 2020 & $\begin{array}{l}\text { PASCOAL, K. } \\
\text { C. F, et al. }\end{array}$ & $\begin{array}{l}\text { O desconhecimento da temática, a falta de fornecimento de } \\
\text { informações básicas durante todo o período da assistência pré-natal, } \\
\text { parto e pós-parto, por parte dos profissionais de saúde e as } \\
\text { consequências de tais condutas foram fatores decisivos para } \\
\text { compreender que a violência obstétrica tem ocorrido rotineiramente. }\end{array}$ \\
\hline
\end{tabular}

Fonte: Pesquisa direta em base de dados. Teresina-PI, 2021.

No Quadro 2 foram organizados os estudos de acordo com o assunto principal destacado em seus conteúdos após leitura completa.

Quadro 2: Organização dos estudos de acordo com o foco das evidências apresentadas. Teresina, 2020.

\begin{tabular}{|l|l|}
\hline ARTIGOS & EVIDÊNCIAS \\
\hline $1,2,3,5,6,7,8,10,11,12,13$ & Violência obstétrica: definições, tipos, características. \\
\hline $1,2,3,4,6,9,12,13$ & Assistência de enfermagem e direitos da gestante. \\
\hline
\end{tabular}

Fonte: Pesquisa direta em base de dados. Teresina-PI, 2021.

De acordo com a organização dos estudos conforme observado acima, foram elaboradas duas categorias para apresentação das evidências e discussão da temática. Na primeira categoria são apresentados: Violência Obstétrica: definição, tipos e características. Já a segunda categoria apresenta: Assistência de Enfermagem e Direitos da gestante.

\section{Discussão}

\subsection{Violência Obstétrica: definição, tipos e características}

A violência obstétrica é caracterizada como uma violência de gênero, em que os atos são praticados contra a mulher no exercício da sua saúde sexual e reprodutiva provocados por profissionais de saúde, servidores públicos, profissionais de corporações públicas e privadas, assim como civis (Nascimento et al., 2017).

De acordo com a Organização Mundial de Saúde (OMS, 2002), violência define-se como a estipulação de grau de dor e sofrimento que podem ser evitados, portanto, a violência contra a mulher, é baseada no gênero e estende-se a lesões físicas, psicológicas, sexuais, que causem dor, sofrimento e morte. 
A violência contra a mulher pode ser classificada como psicológica, física, sexual e verbal, analogamente como negligência, condutas excessivas e desnecessárias, que podem trazer prejuízos para a mãe e para o bebê. Sendo também uma violação dos direitos das mulheres de exercerem sua autonomia e seu poder de decisão sobre seu próprio corpo. Esse tipo de violência também é caracterizado como violência de gênero, por ter uma direção exclusiva a mulher e transpor ligações de poder distintos na sociedade (Narchi et al., 2019).

Assim, o conceito de violência obstétrica é dado como negligência na assistência, discriminação social e também é considerado o uso inadequado de técnicas e procedimentos durante o ciclo gestacional sem a autorização da mulher, ferindo os seus direitos (Andrade et al., 2016).

As violências físicas na obstetrícia são aquelas que provocam algum dano a integridade do corpo feminino, causado de forma não acidental, podendo ser agressões físicas, procedimentos invasivos não autorizados e considera-se também a elevada taxa de parto cesárea, manobra de Kristeller, privação do direito da parturiente de se alimentar ou mover-se (Koperck, et al., 2018).

Ocasionando vários eventos desumanos no período do ciclo gravídico puerperal, sendo estes de origem verbal, como constranger as gestantes por chorar ou gritar de dor, alegria, ansiedade ou emoção durante o trabalho de parto ou parto por meio de xingamentos, humilhações, ameaças, gritos, aplicações excessivas de ocitocina, a ruptura forçada da membrana amniótica para agilizar o trabalho de parto, à manobra de Kristeller, procedimento invasivo e que ocasiona consequências negativas para a parturiente e o bebê (Narchi et al., 2019).

A violência obstétrica verbal e psicológica consiste em ações verbais e comportamentais que provoquem na gestante sentimentos negativos de inferioridade, insegurança, instabilidade emocional, vulnerabilidade e/ou provoque crises de ansiedade e pânico. E, a violência de caráter sexual são as ações que violem o pudor e integridade sexual, como toques em excesso, posição supina durante o parto, episiotomia e assédio (Oliveira et al., 2019).

De acordo com a Defensoria Pública de São Paulo (2017), a violência obstétrica na gestação caracteriza-se por; negar atendimento à mulher ou impor dificuldades ao atendimento; comentários constrangedores à mulher; ofender, humilhar ou xingar a mulher ou sua família; negligenciar o atendimento de qualidade; e agendar cesárea sem recomendação baseada em evidências científicas.

Segundo a pesquisa realizada pela Fundação Perseu Abramo, concluída em 2010, 25\% das mulheres brasileiras sofrem violência no parto e as cesarianas atingem a taxa de 53,7\%. Portanto a violência obstétrica infelizmente é uma realidade no Brasil, sendo realizada através de técnicas desumanizadas, negligência durante a assistência, realização de procedimentos constrangedores ou dolorosos, sem a autorização da mãe, assim como violência verbal e psicológica, implicando diretamente na autonomia e saúde da gestante (Castro \& Rocha, 2020).

Em consonância com os outros autores Sanches et al. (2019) destacam em seus estudos os desafios enfrentados pelas parturientes, como a procura por serviços de qualidade que prestem um atendimento desejado, a insuficiência de informações sobre seus direitos na realização do parto, atitude autoritária por parte dos profissionais. Além disso, os autores fazem uma crítica em relação a boas práticas obstétricas, onde na maioria das instituições a mulher não é o sujeito principal da atenção, priorizando os profissionais, as instituições e seus interesses. Sendo realizadas intervenções, práticas e procedimentos desnecessários.

\subsection{Assistências de Enfermagem e Direitos da Gestante}

O profissional de enfermagem deve priorizar a prática do acolhimento digno e com respeito, fornecendo condições adequadas para que a mulher sinta-se à vontade. Outro cuidado muito importante é garantir a diminuição de procedimentos invasivos, que não seja necessário. Avista disso é papel fundamental do enfermeiro esclarecer e orientar desde a primeira consulta 
sobre todos os procedimentos, para que assim a parturiente possa vivenciar o parto de forma humanizada e respeitosa. (Castro \& Rocha, 2020).

Segundo os autores Lansky, et al. (2019), elencaram em suas pesquisas que essas práticas violentas submetem mulheres a rotinas rígidas e, na maioria das vezes desnecessárias, que não respeitam os seus corpos e os seus ritmos naturais e as impedem de exercerem seu protagonismo, tornando desagradável o momento do parto.

Por tanto, é imprescindível que tanto as mulheres como profissionais tenham conhecimento das leis e das portarias do Ministério de Saúde para que todos fiquem cientes do que pode ou não ocorrer durante todo o ciclo gravídico-puerperal e também saber a quem recorrer caso algo de negativo decorra. A pesquisa destaca a importância da humanização e empatia dos profissionais que participam desse momento, pois diante do medo, duvidas e dificuldades encontradas pelas gestantes são necessárias que o enfermeiro esteja capacitado para dar suporte nesse período tão complexo para muitas mulheres (Simpião \& Vital, 2015).

Segundo a pesquisa realizada pelos autores Almeida, et al. (2020) é notório que a vivência das mulheres neste momento tão importante é acompanhada de altos e baixos e muitos sentimentos são encarados com grande carga emocional, isso deixa as puérperas frágeis e nesse momento o apoio e compreensão dos profissionais de enfermagem é de suma importância. Assim como um tratamento realizado de maneira positiva, com humanização e comprometimento pode gerar tranquilidade à parturiente.

Diante do que foi evidenciado Grecia, et al. (2018), abordam que é importante que o momento do parto possa ser visto e vivido com prazer, que a equipe envolvida na prestação da assistência no momento do parto, possam ser sensíveis para ouvir e acatar as decisões tomadas pela parturiente, compreendendo suas necessidades individuais. Dessa forma, é necessário refletir sobre as técnicas, analisar os procedimentos e orientações aplicadas à mulher durante o processo do pré-parto e parto, tendo como objetivo tornar o nascimento da criança o mais natural e saudável possível.

Os autores Anjos e Gouveia (2018) destacam que é fundamental a humanização no atendimento às mulheres, pois através desse acontecimento é possível garantir um ambiente mais propício para que a gestante exerça autonomia e consiga tomar decisões com tranquilidade. Desse modo, é importante que o profissional estabeleça uma relação de confiança e diálogo com a paciente, acompanhada de afetividade, empatia e sensibilidade, somente assim irá tornar o ambiente mais agradável para a puérpera, possibilitando a ela uma autonomia de vencer os obstáculos encontrados.

O profissional de enfermagem tem respaldo na Lei do exercício profissional n. 7.498 de 25 de junho de 1986 atuando diretamente no cuidado a gestante em trabalho de parto. Sendo assim, é fundamental que o enfermeiro ofereça a assistência necessária e pautada no cuidado integral, humanizado e na ausência de práticas desnecessárias no momento do parto e nascimento, prevenindo a violência obstétrica.

É indubitável que haja humanização no atendimento às mulheres, pois através desse acontecimento é possível garantir um ambiente mais propício para que a gestante exerça autonomia e consiga tomar decisões com tranquilidade. Para isso o profissional deve manter uma relação de diálogo com a paciente, acompanhada de afetividade, empatia e sensibilidade, somente assim ira tornar o ambiente mais agradável para a puérpera, tendo em vista que o trabalho de parto é um momento de profundo estresse para o organismo (Piler et al., 2020).

Quando é necessária a cesariana pode salvar a vida do bebe e da mãe. Porém, se for uma gravidez de baixo risco e que não acompanha complicações, a Organização Mundial da Saúde indica o parto vaginal. Pois a cesariana apresenta riscos de mortalidade e morbidade. No Brasil a mortalidade infantil tem um índice elevado, associado a efeitos da iatrogênia e ao aumento do índice da morbidade materno-infantil, como a internação de bebês em UTI, infecção maternas e a hemorragia (Piler et al., 2020).

A violência obstétrica está cercada de uma gama de vieses e dificuldades, onde na maioria das vezes as mulheres desenvolvem um trauma decorrente a algum momento vivido no parto. Esse estudo destaca a importância da humanização e 
empatia dos profissionais que participam desse momento, pois diante do medo, duvidas e dificuldade encontrada pelas gestantes é necessário que o enfermeiro esteja capacitado para dar suporte nesse período tão complexo para muitas mulheres.

\section{Conclusão}

Com a pesquisa conclui-se que o período gestacional é um momento de êxtase na vida da mulher, onde é necessário ter uma atenção dobrada e especial a saúde da parturiente, sobretudo realizando o acompanhamento do pré-natal e exames necessários, compreendendo sua importância, além disso, o enfermeiro deve orientar e aconselhar a gestante sobre todo o processo que a mesma irá enfrentar até o momento do parto, para que não haja dúvidas para a mãe.

Notou-se no estudo, que as gestantes possuem pouco conhecimento sobre o momento do parto e como ele é conduzido, o que reflete para ocorrência da violência obstétrica. Foram observados que ainda existe uma escassez de educação em saúde na atenção primária, por parte do profissional Enfermeiro, voltado para a importância do diálogo e acolhimento durante a gestação, visto que o Enfermeiro é o principal educador em saúde. Desta forma, visa à necessidade de capacitar os profissionais da atenção primária, em especial o enfermeiro, para um novo modelo de assistência de forma que ajudam as gestantes a perder o medo de viver a experiência do parto.

Desse modo, é necessário que os profissionais realizem novas estratégias como atividades educativas, palestras, banners, folders e orientações durante as consultas de pré-natal, enfatizando a importância de exercerem seus direitos.

Para isso, o Enfermeiro deve ter um diálogo reflexivo juntamente com a paciente transpassando conhecimento, esclarecendo dúvidas, além de estabelecer um vínculo de confiança contribuindo para a experiência incrível do parto sem violência. Neste sentido, sugere-se que haja a ampliação dos estudos abordando a temática e buscando por mais conhecimentos cuja finalidade seja preparar a enfermagem para atuar no combate a violência obstétrica.

\section{Referências}

Aguiar, J. M., D’ Oliveira A. F. P. L. \& Schraiber, L. B. (2013). Violência institucional, autoridade médica e poder nas maternidades sob a óticados profissionais de saúde. Cad. Saúde Pública. 29(11), 2287-2296.

Almeida, S. S. R., Reticena, K. O., Gomes, M. F. P., \& Fracolli, L. A. (2020). Vivências de puérperas frente à atuação da equipe de enfermagem durante o trabalho de parto. Revista online de pesquisa: cuidado é fundamental, 12, 350-354.

Andrade, P. O. N., Silva, J. Q. P., Diniz, C. M. M., \& Caminha, M. F. C. (2016). Fatores associados a violência obstétrica na assistência do parto vaginal em uma maternidade de alta complexidade em Recife, Pernambuco. Rev. Bras. Saúde Matern. Infant, 16(1), 29-37.

Anjos, M. A., \& Gouveia G. H. (2019). Presença do acompanhante durante o processo de parturição e nascimento: análise da prática. Rev enferm UERJ, $27, \mathrm{e} 38686$.

Bohren, M. A., Vogel, J. P., Hunter, E. C., Lutsiv, O., Makh S. K., Sousa, J. P., Aguiar, C., Coneglian, F. S., \& Diniz, A. L. A. et al. (2015). The mistreatment of women during childbirth in healthy facilities globally:a mixed-methods systema ticreview. Plosmed, $12(6)$, e1001847.

Brito, C. M. C., Oliveira, A. C. G. A., \& Costa, A. P. C. A. (2020). Violência obstétrica e os direitos da parturiente: o olhar do poder judiciário brasileiro. Cad. Ibero-amer. 9(1), 120-124.

Castro, B. T. A., \& Rocha, P. S. (2020). Violência obstétrica e os cuidados de enfermagem: reflexões a partir da literatura. Enfermagem em foco, 11(1), $176-181$.

Cunha, A. L., Henriques, R. B. L., Silva, T. R. D, Silva, M. R. B., Tertulliano, K., \& Armada e Silva, H. C. D. (2020). Produção de conhecimento sobre violência obstétrica: o lado invisível do parto. Revista nursing, 23(260), 2329-3532.

Defensoria Pública do estado de São Paulo. (2017). Violência obstétrica: você sabe o que é?. Núcleo Especializado de Promoção e Defesa dos Direitos da Mulher e Associação Artemis. São Paulo -SP: Defensoria Pública.

Fernandes, I. B., Bento, P. A. S. S., \& Xavier, R. B. (2019). Experiência das mulheres no gestar e parir fetos anencéfalos: as múltiplas faces da violência obstétrica. Interface, 23(14), e170757.

Grecia, R. M. L., Neto, D. L., Dias, V. P. \& Moisés, M. S. (2019). Percepção e ações de doulas no processo de humanização do parto. Revista mineira de Enfermagem, 23, e1209.

Jardim, N. M. B., \& Modena, C. M. (2018). A violência obstétrica no cotidiano assistencial e suas características. Revista latino-americano de enfermagem, 26, e3069. 
Koperck,C.S., Matos, G.C., Soares, M. C., Escobal, A. P. L., Quadro, P. P., \& Cecagno, S. (2018). A violência obstétrica no contexto multinacional. Revista de Enfermagem UFPE on line, 12 (7), 2050-2060.

Lanky, S., Souza, K. V., Peixoto, E. R. M., Oliveira, B. J., Diniz, C. S. G., Vieira, N. F., \& Cunha, R. O. et al. (2019). Violência obstétrica: influência da exposição sentidos do nascer na vivência das gestantes. Ciência de Saúde Coletiva, 24(8), 2811-2823.

Moura,R. C. M., Pereira, T. F., Rebouças, F. J., Costa, C. M., Lernades, A. M. G., Silva, L. K. A., \& Rocha, K. M. M. (2018). Cuidados de enfermagem na prevenção da violência obstétrica.Enferm.foco.natal, 9(4), 60-65.

Narchi z, N., Venâncio, K. C. M. P., Ferreira, F. M., \& Vieira, J. R. (2019). O Plano individual de parto como estratégia de ensino-aprendizagem das boas práticas de atenção obstétrica. Rev Esc Enferm USP, 53, e03518.

Nascimento, S. L, Pires, V. M. M. M., Santos, N. A., Machado, J. C., Meira, L. S., \& Palmarella, V. P. R. (2019). Conhecimentos e experiências de violência obstétrica em mulheres que vivenciaram a experiência do parto. Revista enfermería actual, 37, 66-79.

Oliveira, M. S. S., Rocha, V. S. C., Arrais, T. M. S. N.,Alves, S. M., Marques, A. A., Oliveira, D. R., \& Santana,M. D. R. (2019). Vivências de violência obstétrica experimentadas por parturientes. Abcs Health SCI, 44(2), 114-119.

Pascoal, K. C. F., Filgueiras, T. F., Carvalho, M. A., Candeia, R. M. S., Pereira, J. B., \& Cruz, R. A. O. (2020). Violência obstétrica na percepção de puérperas. Revista Nursing, 23(265), 4221-4226.

Piler, A. A; Wall, M. L., Aldrighi, J. D., Benedet, D. C. F., Silva, L. R., \& Szpin, C. C. (2019). Protocolo de boas práticas obstétricas para os cuidados de enfermagem no processo de parturição. Revista Mineira de Enfermagem. 23, e1254.

Programa Das Nações Unidas Para O Desenvolvimento, Ipea-Instituto de Pesquisa Econômica e Aplicada. (2019). Relatório do desenvolvimento humano 2019. Brasilia - DF

Rodrigues, F. A. C., Lira, S. V. G., Magalhães, P. H., Freitas, A. L. V., Mitros, V. M. S., \& Almeida, P. C. (2017). Violência obstétrica no processo de parturição em maternidades vinculadas à rede cegonha. Reprodução \& climatério, 32(2), 78-84.

Sanches, M. E. T. L., Barros, S. M. O., Santos, A. A. P., \& Lucena, T. S. (2019). Atuação da enfermeira obstétrica na assistência ao trabalho departo e parto. Revista Enfermagem UERJ, 27, e43933.

Sena, L.M., \& Tesser, C. D. (2017). Violência obstétrica no brasil e ciberativismo de mulheres. Interface, 21(60) 209-20.

Silva, F. C., Viana, M. R. P., Amorim, F. C. M., Veras, J. M. M. F., Santos, R. C., \& Sousa, L.L. (2019). O saber das puérperas sobre violência obstétrica. Revista de Enfermagem UFPE online, 13, 1-6.

Silva, J. B., Moraes, M. N., Brandão, B. M. L. S., Freitas, W. M. F., Souto, R. Q., \& Dias, M. D. (2020). Mulheres em privação de liberdade: narrativas de des(assistência) obstétrica. Rev Min Enf, 24, e1346.

Teixeira, P. C., Antunes, L.S., Duamarde, L. T. L., Velloso, V., Faria, G. P. G., \& Oliveira, T. S. (2020). Percepção das parturientes sobre violência obstétrica: a dor que querem calar. Revista Nursing, 23(261). 3607-3615. 